\title{
Rancangan Sistem Informasi Keuangan dalam Organisasi Mahasiswa
}

\author{
Rama Yudha Pratama \\ Telkom University; \\ Email: ramayudha@telkomuniversity.ac.id
}

\begin{abstract}
Organisasi Mahasiswa merupakan wadah bagi mahasiswa untuk mengembangkan kapasitasnya bisa berupa aspirasi, gagasan-gagasan, mencari pengalaman dan tujuan positif lainnya. Oleh karena itu penting adanya organisasi mahasiswa ini, didalam organisasi pastinya ada uang kas, uang kas ini sendiri berguna untuk keperluan-keperluan organisasi atau jika ada kebutuhan mendadak. Dengan adanya perkembangan teknologi membuat manusia berfikir untuk dapat bekerja lebih efektif dan efisien. Salah satunya yaitu membuat sistem konvensional menjadi sistem yang terkomputerisasi. Dengan memanfaatkan fasilitas website yang terhubung ke internet, informasi seputar keuangan organisasi tersebut dapat disampaikan dengan lebih efektif dan efisien dan dapat melakukan pembayaran juga.
\end{abstract}

Pada penelitian ini dirancang suatu sistem informasi berbasis web menggunakan bahasa pemrograman Microsoft Access. Dengan sistem ini, diharapkan mampu mengatasi berbagai kebutuhan dari user untuk melihat biaya kas yang belum dibayar termasuk dendanya jika telat dan melakukan pengecekan biaya selanjutnya yang akan dilakukan oleh organisasi tersebut.

Dari hasil penelitian yang telah dilaksanakan penulis akan mengimplementasikan hasil penelitian tersebut kedalam PerancanganSistem Informasi Perpustakaan Berbasis Web di Telkom Univerisity

Keywords: Microsoft Access, Organisasi Mahasiswa, Waterfall Model, Sistem Informasi

Paper ini akan dipublikasikan di osf.io [1] menggunakan format standard perancangan sistem informasi [2]

\section{Introduction}

1.1. Business case

Project Definition: Organisasi Mahasiswa merupakan wadah bagi mahasiswa untuk mengembangkan kapasitasnya bisa berupa aspirasi, gagasan-gagasan, mencari pengalaman dan tujuan positif lainnya. Oleh karena itu penting adanya organisasi mahasiswa ini, didalam organisasi pastinya ada uang kas, uang kas ini sendiri berguna untuk keperluan-keperluan organisasi atau jika ada kebutuhan mendadak. Dalam praktiknya bendahara sulit untuk menagih anggota organisasi untuk membayar uang kas pada waktu tersebut dan memberitahu keperluan apa saja, jumlah dan kapan pembayaran terakhirnya. Disini kamu membuat website dimana setiap anggota organisasi login dengan NIM dan setalah login mereka dapat melakukan pembayaran secara online kemudian anggota juga dapat melihat postingan kapan akan ada pembayaran, jumlah dan terakhir pembayarannya. Jika telat membayar maka jumlah pembayarannya akan bertambah sesuai dengan dendanya.

Project Objective: membuat website berbasis data yang dapat memberikan informasi mengenai jumlah pembayaran, terakhir pembayaran, denda, kapan pembayaran keperluan diluar kas (membeli jaket organisasi, dll.)

- $\quad$ Dapat mengetahui kapan pembayaran dilakukan

- Dapat mengetahui berapa jumlah yang harus dibayar 

- $\quad$ Anggota dapat mengetahui pembayaran selanjutnya kapan dan terakhir pembayarannya 1.2. System Requirement
System Function: Explains the specific and detailed system function.
Website Organisasi merupakan website system informasi berbasis data yang memiliki fungsi
1. Melakukan pembayaran secara online
2. Melakukan pengumuman untuk pembayaran selanjutnya, jumlah dan untuk apa uangnya
3. Menampilkan bukti telah membayar

System Feature: Explains the specific and detailed system features.

Website Organisasi memiliki fitur sebagai berikut :

1. Memiliki data informasi anggota organisasi tersebut seperti nama, NIM, dan jabatan

2. Memiliki data informasi keuangan yang sudah dilakukan oleh tiap anggota

3. Memiliki data informasi tiap pembayaran

Acceptance Criteria: Explains the specific and detailed system acceptance criteria

Untuk dapat memasukkan data ke website, hannya dilakukan oleh NIM yang sudah terdaftar. Berikut merupakan penggunaan website organisasi:

1. Aplikasi akan meminta login terlebih dahulu (memasukkan NIM dan password)

2. User/ mahasiswa yang telah login dapat melihat jumlah pembayaran uang kas, denda, terakhir pembayaran dan postingan pembayaran selanjutnya dan nominalnya

3. User dapat melakukan pembayaran.

4. User dapat mendownload bukti pembayaran jika sudah melakukan pembayaran.

System user level: Explains the specific and detailed user level that will using the system

Website Organisasi memiliki 2 tingkatan pengguna sebagai berikut :

1. Admin (Bendahara)

Merupakan user dengan kedudukan yang paling tinggi dan memiliki semua akses. Bertanggung jawab mengelola informasi terkait keuangan pada website tersebut.

2. User (Anggota Organisasi)

User yang menggunkan website sesuai dengan fungsinya tanpa bisa mengatur isi dari website tersebut. User disini harus melakukan login untuk memastikan bahwa user merupakan anggota dari organisasi tersebut.

\section{Penjelasan SIngkat Terkait Metode}

SDLC atau Systems development life cycle digunakan untuk membangun suatu sistem informasi agar dapat berjalan sesuai dengan apa yang diharapkan.

Metode yang digunakan adalah Waterfall Model, Waterfall Model ini melibatkan penyelesaian satu tahap secara lengkap sebelum melangkah ke tahap berikutnya. Ketika satu tahap selesai langsung dilakukan evaluasi untuk memastikan proyek berjalan sesuai rencana dan layak diteruskan ke tahap berikutnya. Waterfall Model, disebut juga model klasik, memiliki beberapa tahap utama, yaitu analisis dan rekayasa sistem, perancangan, penulisan program, pengujian, dan pemeliharaan. 


\section{SDLC- WATERFALL MODEL}

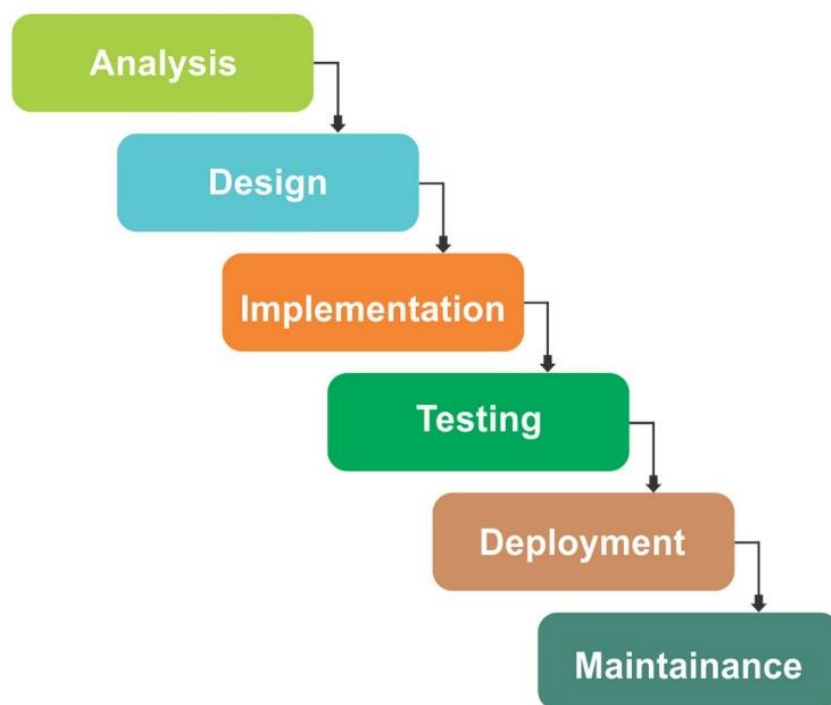

Figure 1 Waterfall Model

\section{Proses Perhitungan}

\subsection{System Design}

Design System adalah suatu kumpulan komponen-komponen $\mathrm{UI}$ dan code yang saling terhubung kemudian dikategorikan oleh suatu standarisasi yang jelas dan terintegrasi dalam suatu sistem. Design system ini dapat digunakan berulang kali oleh desainer ataupun developer dalam pengembangan produk.

Beberapa fungsi utamanya yaitu

\section{Efficiency}

Design system tentu saja akan lebih menghemat banyak waktu dan biaya ketika mengembangkan suatu produk, hal ini dapat menjadi benefit bagi bisnis.

\section{Easy to Scale}

Selain itu, design system dapat mengakomodir suatu permasalahan yaitu design team yang mulai berkembang, tuntutan multiplatform dan berkembangnya suatu produk seiring dengan perkembangan kebutuhan bisnis.

3. Concistency - Dalam sebuah design team yang sudah cukup besar, pastinya memiliki banyak desainer dan memiliki pandangan desain yang berbeda-beda.

\subsection{Data Flow Diagram (DFD)}

Data Flow diagram atau biasa disebuat DFD adalah diagram yang memberikan visual tentang aliran data dan informasi dari suatu system. Visual dari DFD sendiri menggambarkan siapa saja yang terlibat pada system tersebut dari input sampai output. DFD biasanya digunakan untuk membuat sebuah system yang baru akan dikembangkan. 
DFD LEVEL 0

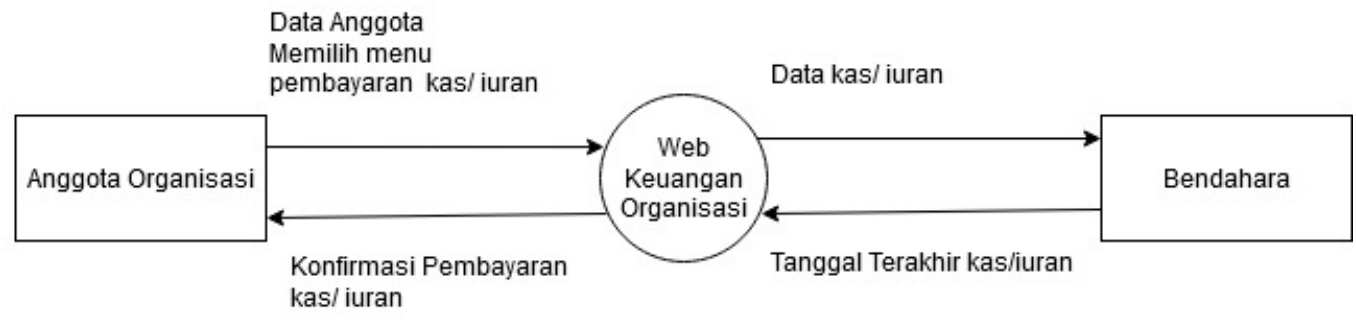

DFD LEVEL 1
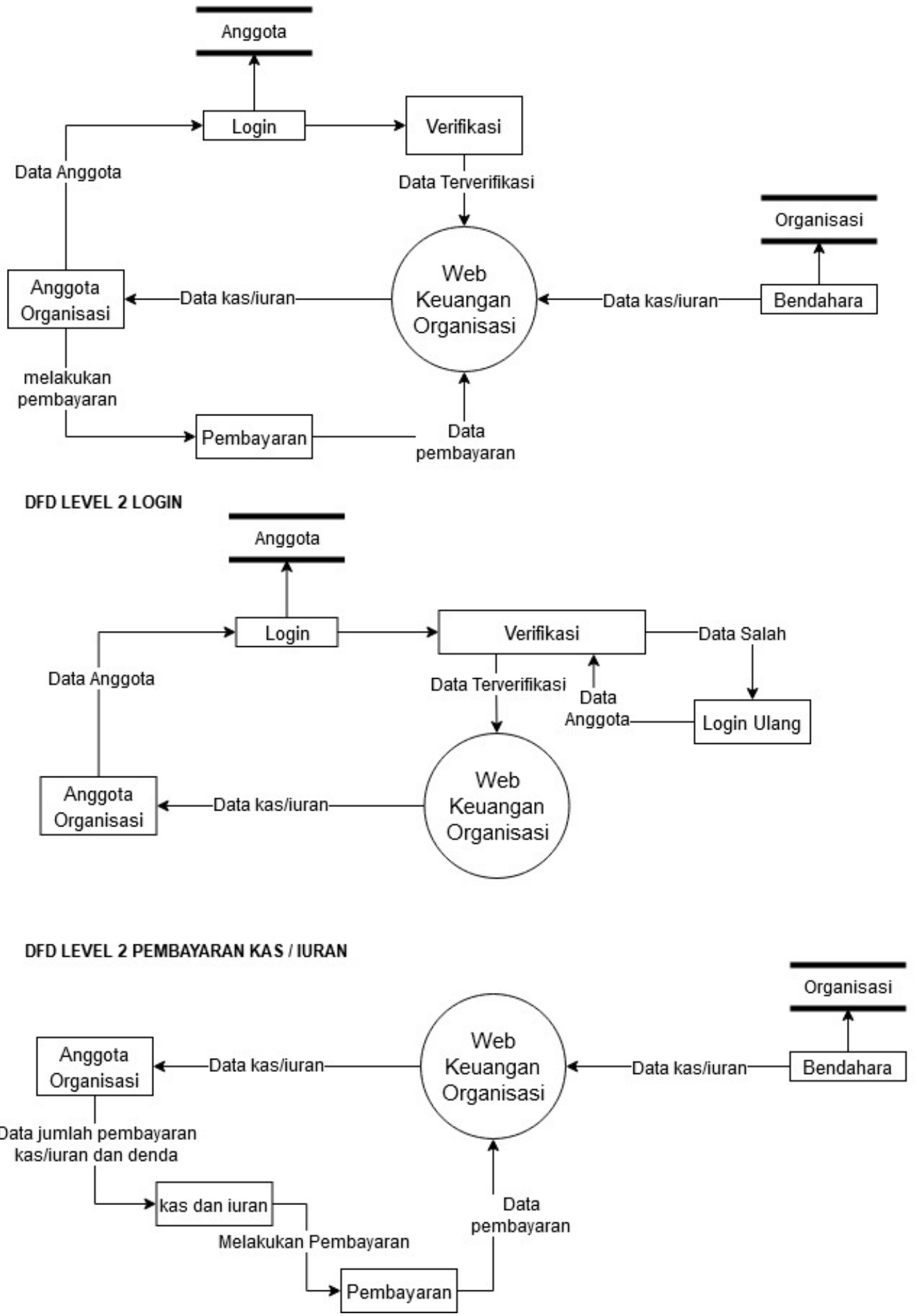

Figure 2 Gambar Data Flow Diagram 
3.3. Entity Relationship Diagram (ERD)

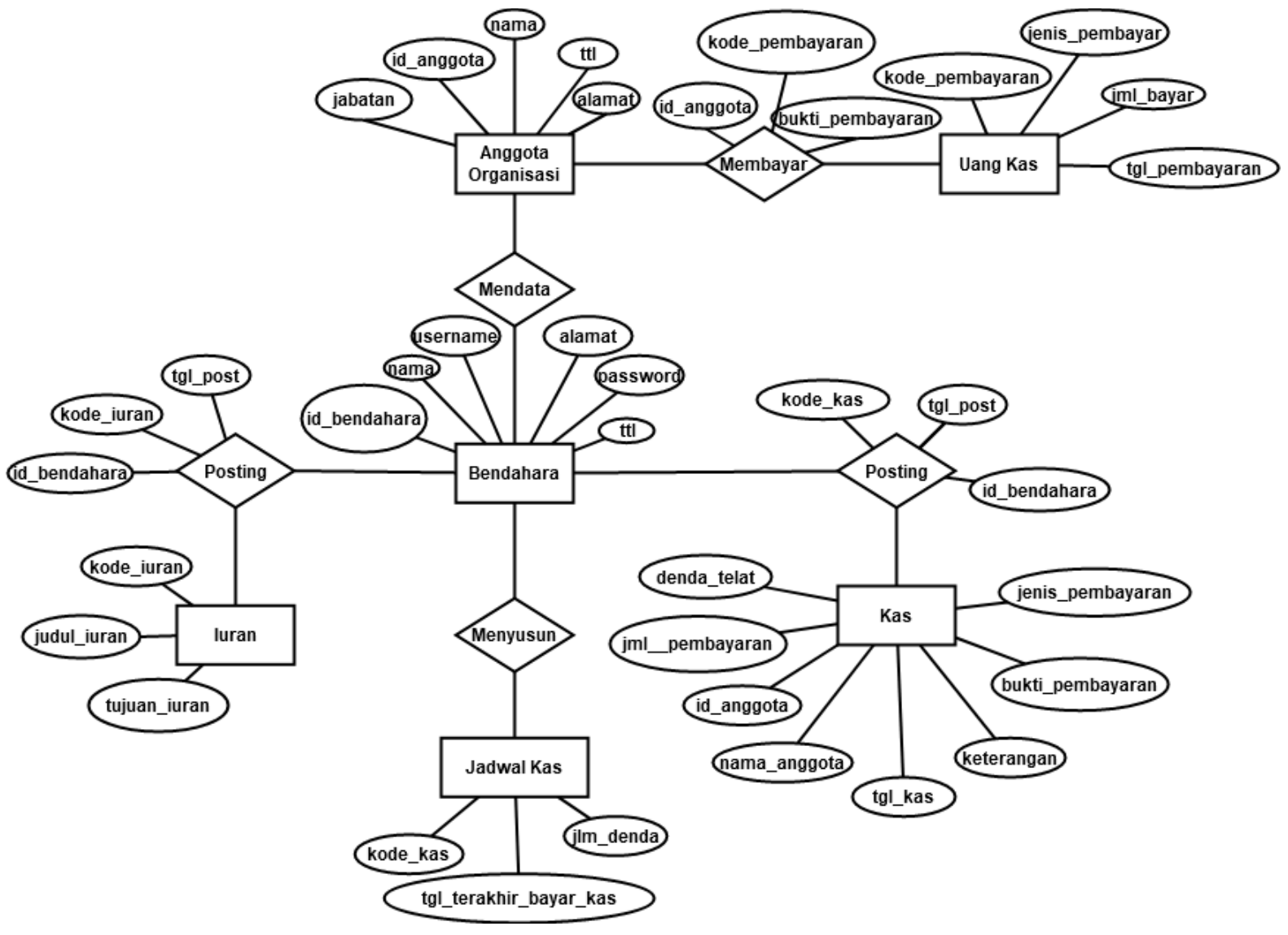

Figure 3 Gambar ERD

Entity Relationship Diagram atau ERD adalah sebuah model yang berfungsi untuk menyusun database agar dapat menggambarkan data yang mempunya relasi dengan database yang akan didesain

3.4. Database Design

Data Objects and File and Database Structures 

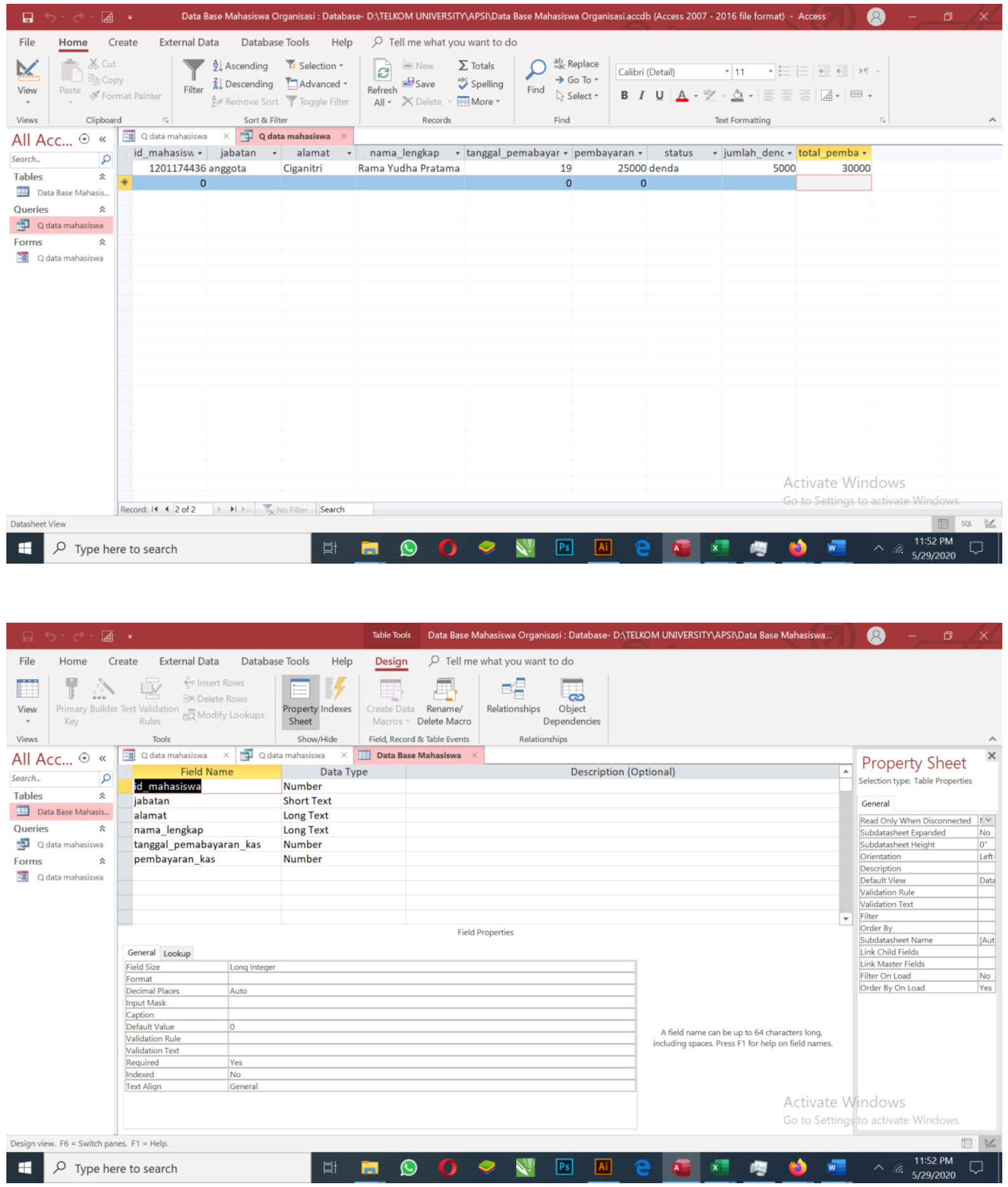

Figure 4 Gambar Use Case Diagram

\subsection{Use Case Diagram}

Use Case Diagram adalah pemodelan untuk menggambarkan behaviour/kelakuan system yang akan dibuat. Use case Diagram juga menggambarkan interaksi antara satu atau lebih actor dengan system yang akan dibuat. 


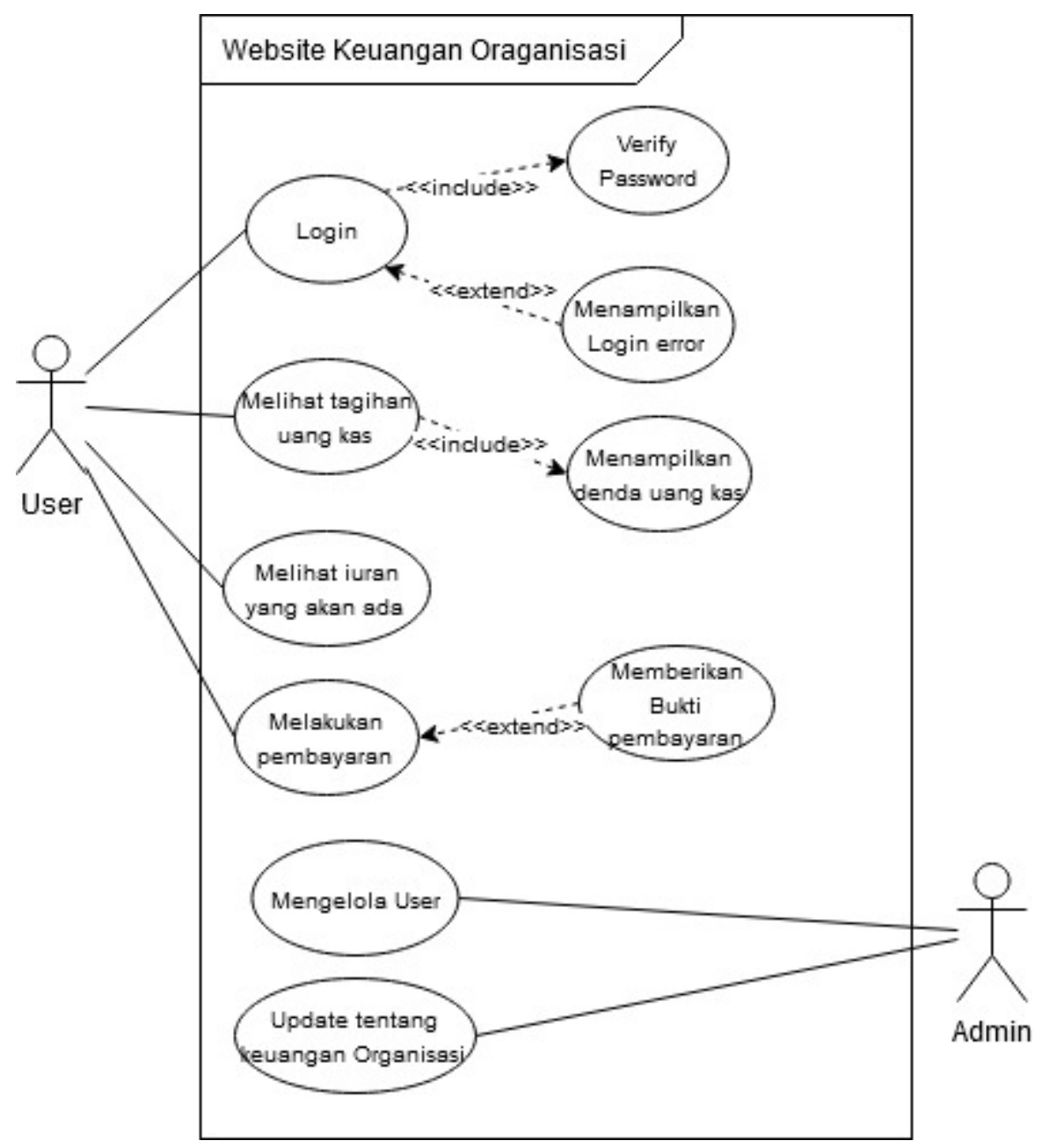

Figure 5 Gambar Use Case Diagram

\subsection{Activity Diagram}

Activity diagram merupakan rancangan aliran aktivitas atau aliran kerja dalam sebuah sistem yang akan dijalankan. Activity Diagram juga digunakan untuk mendefinisikan atau mengelompokkan aliran tampilan dari sistem tersebut. Activity Diagram berfungsi untuk memperlihatkan urutan aktifitas proses pada sistem. 


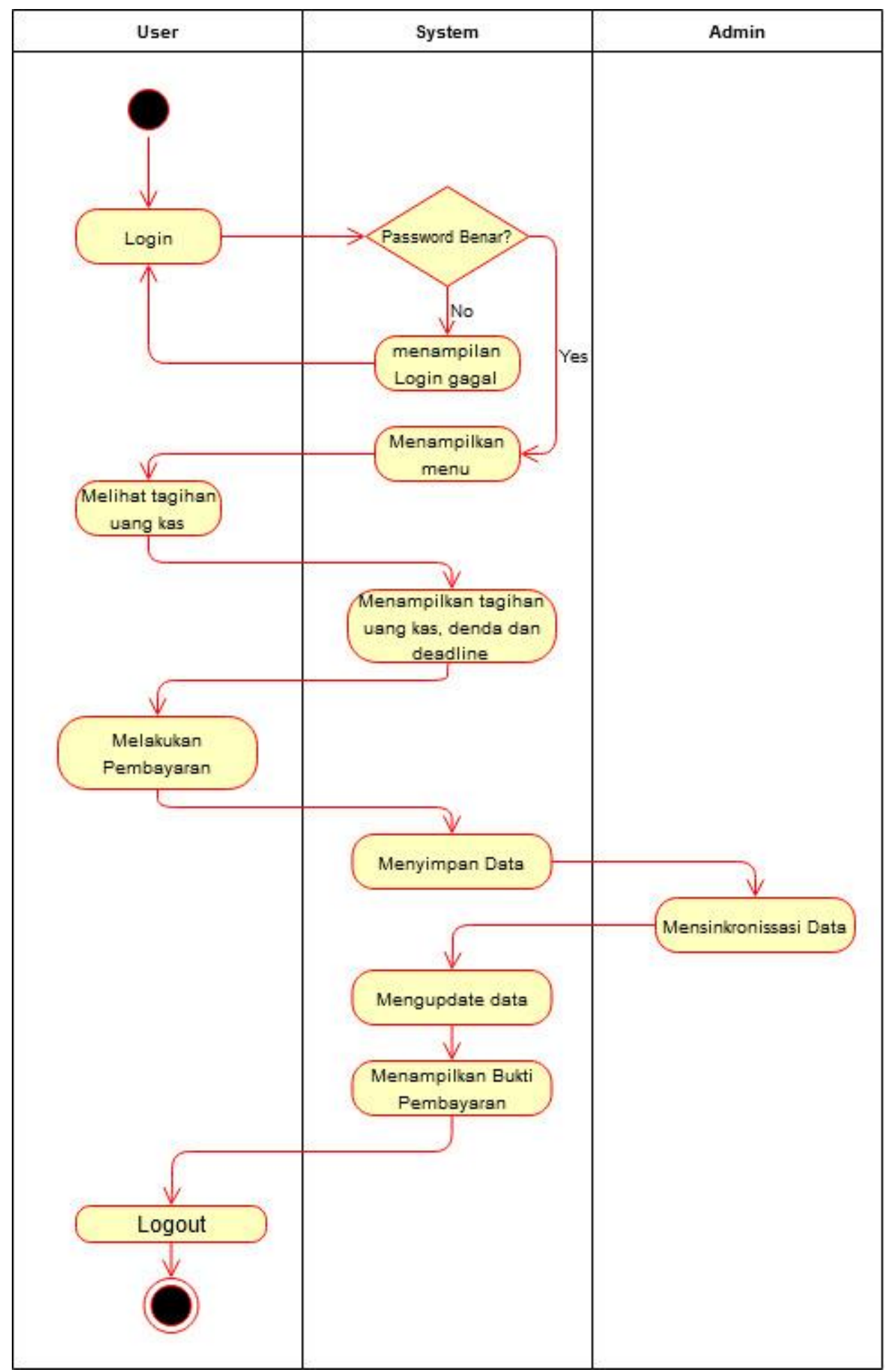

Figure 6 Gambar Activity Diagram

\subsection{Sequence Diagram}

Sequence Diagram adalah diagram yang menggambarkan kolaborasi dinamis antara sejumlah objek. Salah satu fungsi dari sequence diagram adalah untuk menganalisa, mendesain dan memfokuskan pada identifikasi sebuah metode yang digunakan sistem. 


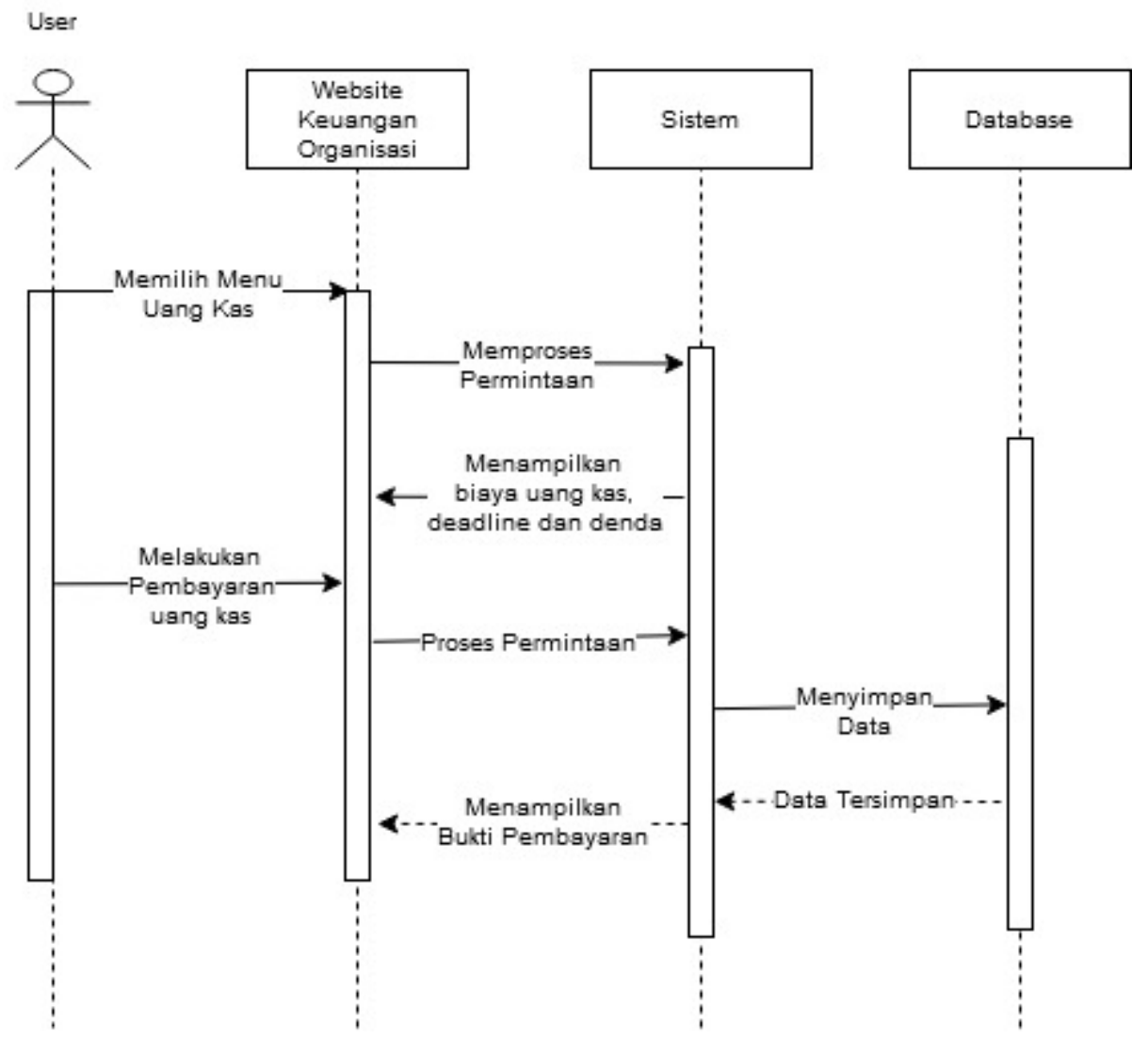

Figure 7 Gambar Sequece Diagram

\subsection{Interface Design}

-Interface Architecture, Interface Detailed Design (with screenshots), Provide the screenshots of the system

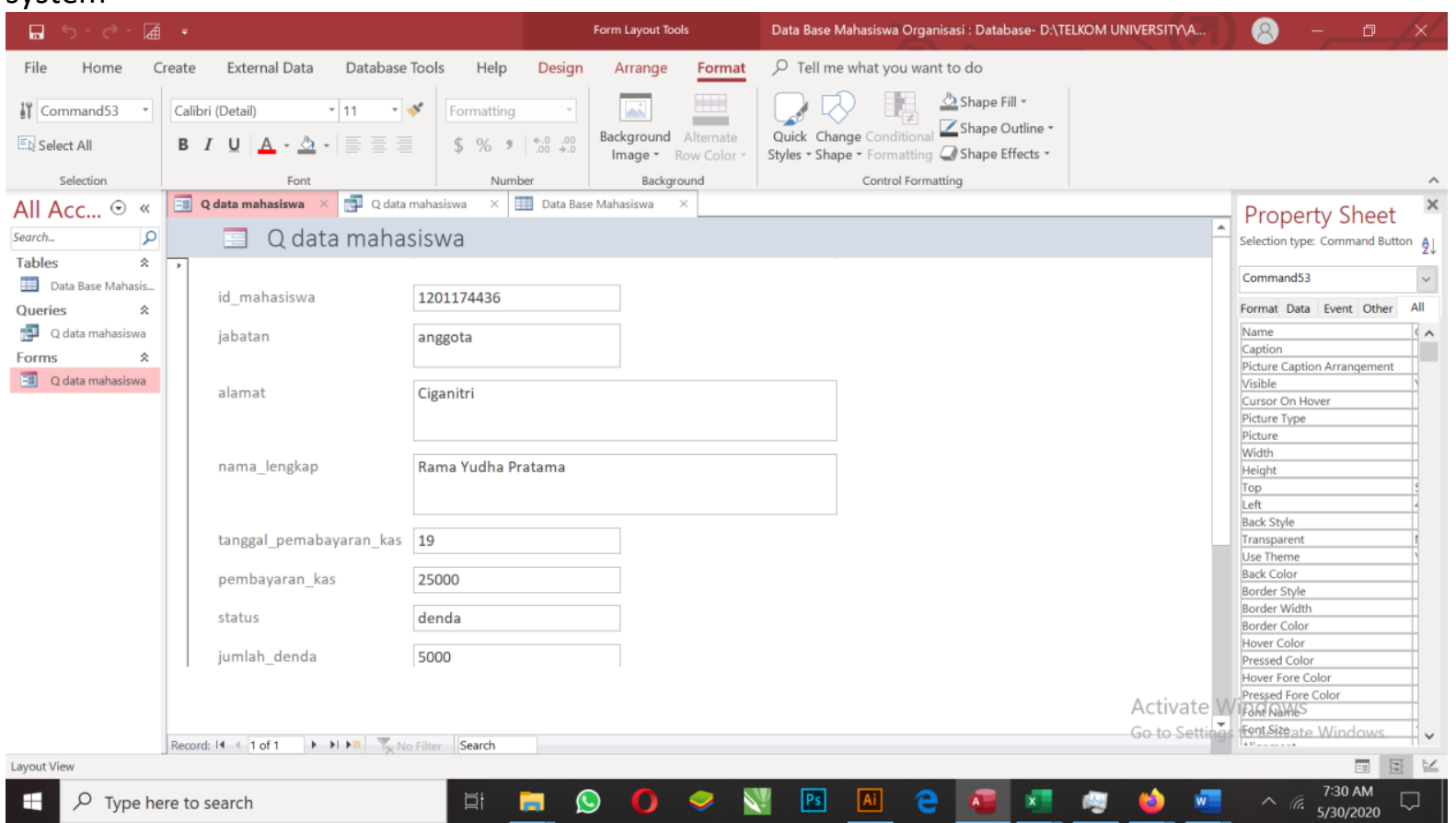

Figure 8 Gambar Form 


\subsection{Source Code}

Pada Code disini membutuhkan id_mahasiswa, jabatan, alamat, nama_lengkap, tanggal_pembayaran, batas_tanggal_pembayaran. Code yang saya masukkan apabila batas tanggal pengeluaran dikurangi tanggal pembayaran ' $\geq 0$ ' maka status yang ditampilkan tidak denda dan tidak mendapat biaya tambahan sedangkan jika hasilnya ' $<0$ ' maka status yang ditambulkan denda dan mendapat biaya tambahan sebesar denda tersebut dalam kasus ini saya gunakan denda Rp 5.000 pada anggota yang telat membayar kas

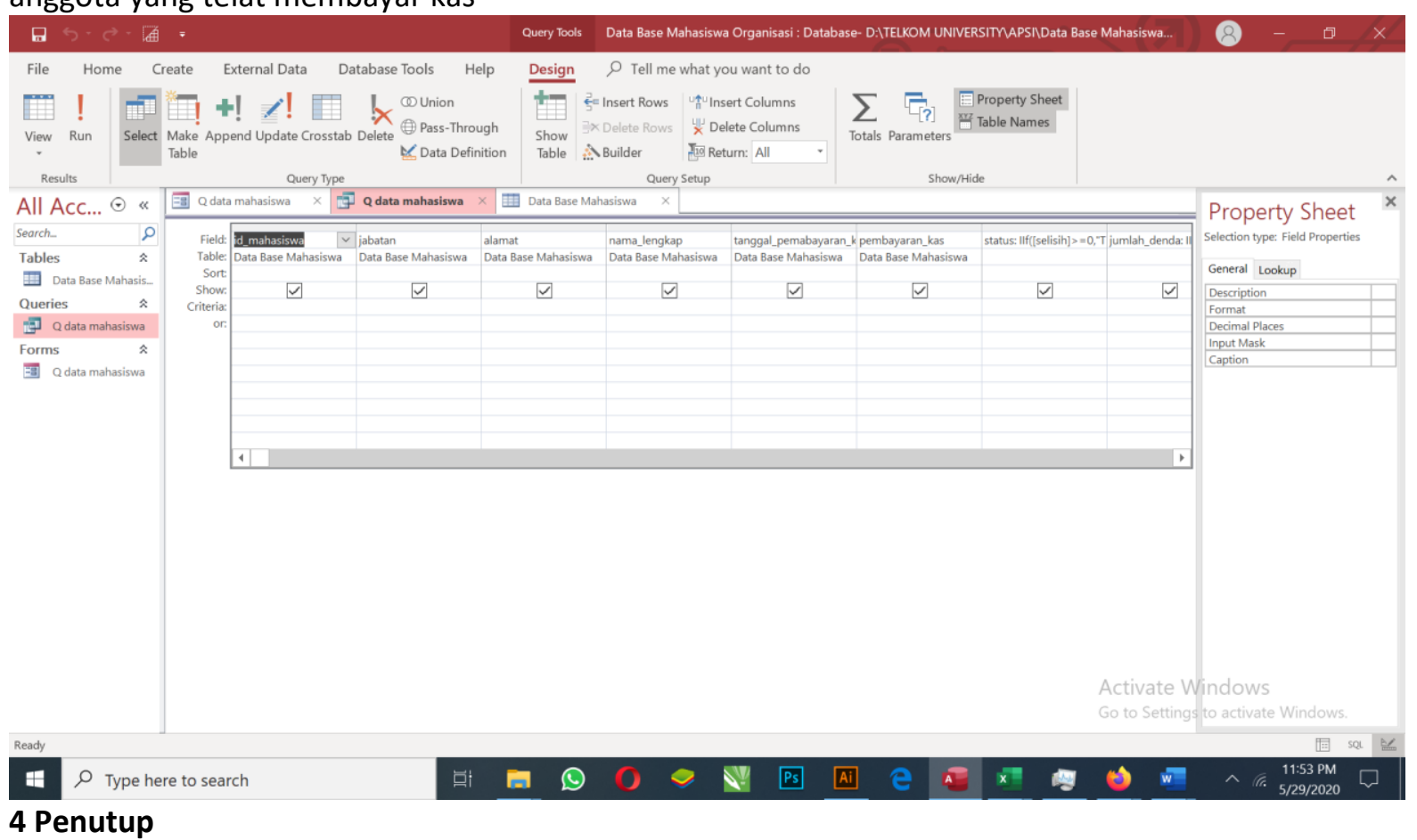

\subsection{Kesimpulan}

Perancangan Sistem Informasi uang kas/keuangan di organisisasi mahasiswa merupakan perancangan dari sistem yang sedang berjalan tetapi masih konvensional. Berbagai permasalahan yang muncul telah diupayakan untuk dapat ditangani dengan sistem yang baru ini, adapun kesimpulan yang dapat diambil anatara lain :

- Sistem yang dirancang ini adalah sistem informasi web keuangan dari organisasi mahasiswa. Sistem ini dapat memberikan beberapa kelebihan dibandingkan dengan sistem yang sedang berjalan saat ini, yaitu efisien dan efektif dalam pengolahan informasi.

- Dengan adanya sistem informasi web keuangan organisasi ini dapat membantu mempermudah anggota maupun bendahara dalam proses mendapatkan informasi dan pengelolaan data uang kas dan biaya yang ada lainnya.

\subsection{Saran}

Penulis menyadari bahwa pada sistem informasi keuangan organisasi ini masih memiliki beberapa kekurangan, untuk itu apabila penelitian ini ingin dilanjutkan, penulis akan memberikan beberapa saran mengenai bagian-bagian yang sebaiknya ditingkatkan, yaitu :

- Dalam tahap pengembangan selanjutnya, disarankan bagi siapa saja yang akan meneruskan sistem informasi persediaan barang ini dapat menambahkan denda yang berlipat secara otomatis, dalam penelitian kali ini belum ada denda yang berlipat jika telat terus hanya ditambahkan denda yaitu Rp 5.000 saja.

- Perlu adanya pengembangan dan pemeliharaan yang lebih baik lagi terhadap sistem yang telah dibuat, sehingga sistem dapat dipergunakan sesuai dengan kebutuhan.

\section{References}


[1] R. Aurachman, "Review Terhadap OSF.IO Sebagai Sarana Publikasi Preprint," OSF Preprints, 17 May 2020.

[2] R. Aurachman, "Kerangka Perancangan Sistem Informasi Sebagai Pembelajaran Mahasiswa Teknik Industri," osf.io, 52020.

[3] https://www.dewaweb.com/blog/entity-relationship-diagram/

[4] http://www.materidosen.com/2017/04/use-case-diagram-lengkap-studi-kasus.html

[5] https://socs.binus.ac.id/2019/11/22/uml-diagram-activity-diagram/

[6] https://www.codepolitan.com/belajar-uml-sequence-diagram-57fdb1a5ba777-17044

[7] https://ngampus.id/contoh-sequence-diagram/

[8] https://medium.com/codelabs-unikom/dspart1-6d80d7762cf2

[9]

Additional

[a] R. Aurachman, "Review Terhadap OSF.IO Sebagai Sarana Publikasi Preprint," OSF Preprints, 17 May 2020. doi:10.31219/osf.io/rvumx , Available: https://osf.io rvumx

[b] R. Aurachman, "Kerangka Perancangan Sistem Informasi Sebagai Pembelajaran Mahasiswa Teknik Industri," osf.io, doi:10.31219/osf.io/tmpen , 5 2020. Available: https://osf.io/tmpen 